Regular Article

\title{
Development of high flux nanofiltration membranes through single bilayer polyethyleneimine/alginate deposition
}

\author{
Önder Tekinalp, Sacide Alsoy Altinkaya* \\ Department of Chemical Engineering, Izmir Institute of Technology, Gulbahce Campus, 35430 Urla, Izmir, Turkey
}

\section{H I G H L I G H T S}

- Polyethyleneimine and alginate pair were deposited on a tight ultrafiltration membrane.

- Antifouling nanofiltration membrane with a MWCO of 1000 Da and $15.5 \mathrm{~L} / \mathrm{m}^{2} \cdot \mathrm{h} \cdot$ bar PWP was obtained. - Reactive red 141, Brilliant blue G and Congo red dyes were completely removed.

- The membrane showed resistance to damage by high salt concentration and hydrochloric acid.

\section{A R T I C L E I N F O}

\section{Article history:}

Received 16 May 2018

Revised 25 October 2018

Accepted 27 October 2018

Available online 29 October 2018

\section{Keywords:}

Nanofiltration

Layer by layer polyelectrolyte deposition

Thin film composite membrane

Dye rejection

Polyethyleneimine/alginate

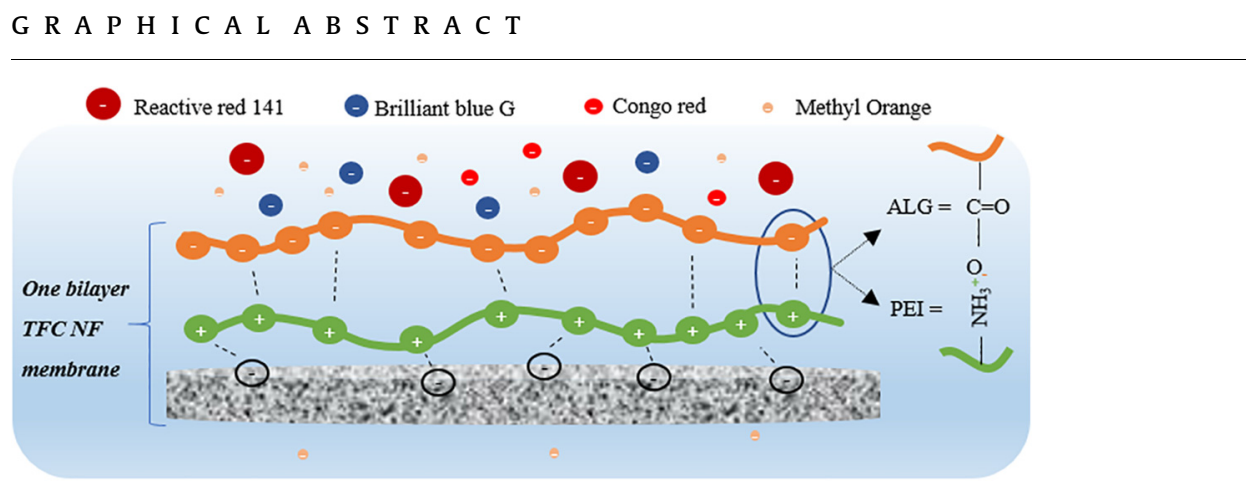

\begin{abstract}
A B S T R A C T
The aim of this study is to prepare high flux, stable, antifouling nanofiltration membranes through single bilayer polyelectrolyte deposition. To this end, a tight ultrafiltration support membrane was prepared from a polysulfone/sulfonated polyethersulfone blend. Deposition of a polyethyleneimine and alginate pair on this support has reduced the molecular weight cut off from $6 \mathrm{kDa}$ to below $1 \mathrm{kDa}$. The pure water permeability and polyethylene glycol 1000 rejection of the coated membrane were found to be $15.5 \pm 0.3 \mathrm{~L} / \mathrm{m}^{2} \cdot \mathrm{h} \cdot$ bar and $90 \pm 0.6 \%$, respectively, by setting the deposition pH for each layer to 8 and the ionic strengths to $0.5 \mathrm{M}$ and $0 \mathrm{M}$. This membrane has exhibited significantly higher permeability than commercial membranes with the same molecular weight cut off, retaining $98 \%$ of the initial flux during $15 \mathrm{~h}$ filtration of bovine serum albumine. In addition, the membrane has been able to completely remove anionic dyes from aqueous solution by showing $99.9 \%$ retentions to Reactive red 141, Brilliant blue $\mathrm{G}$ and Congo red with a 2 bar transmembrane pressure. High flux and membrane stability in acidic and salty environments have been achieved when deposition conditions favor high adsorption levels for the first layer and strong ionic cross-linking between the carboxyl group on the alginate and the amine groups on the polyethyleneimine.
\end{abstract}

(c) 2018 Elsevier Inc. All rights reserved.

\section{Introduction}

Nanofiltration (NF) membranes are used in applications such as water softening, brackish water reclamation, dye salt separations and recovery of valuable low molecular weight $(<1500 \mathrm{~g} / \mathrm{mole})$

\footnotetext{
* Corresponding author.

E-mail address: sacidealsoy@iyte.edu.tr (S. Alsoy Altinkaya).
}

biopharmaceuticals and nutraceuticals [1,2]. To extend the use of NF, high-flux, stable and fouling resistant membranes, that can be easily manufactured are needed. Most of the NF membranes are produced in the form of a thin film composite (TFC) structure which consists of a porous support and a thin selective layer. The layer by layer ( $\mathrm{LbL}$ ) deposition of polyelectrolytes on ultrafiltration (UF) membranes is an attractive technique to manufacture TFC NF membranes. This is due to flexibility of the method in controlling 
the morphology of the layers and the binding strength between the layers by carefully selecting the deposition conditions and polyelectrolyte pairs. In addition, the thickness of deposited layers is usually on the order of a few nanometers, which minimizes mass transfer resistanceand prevents significant decline in flux. One of the most significant limitations of the technique is the multiple number of layers that needs to be deposited in order to obtain desired pore size required for NF. This leads to an impractically long deposition process and increases the cost of production. In addition, poor stability of the LbL deposited NF membranes is a concern for long term usage under harsh conditions.

Currently, one of the principal applications of NF is reported to be retention and concentration of the dyes used in the textile industry. Several groups have utilized the LbL technique for preparing TFC NF membranes for dye retention. Guo et al. [3] adsorbed 9 layers of polyethyleneimine (PEI) and sulfonated formaldehyde on a $100 \mathrm{kDa}$ polyacrylonitrile (PAN) support. After crosslinking the membrane with glutaraldehyde, they reported a pure water permeability (PWP) of $4.93 \mathrm{~L} / \mathrm{m}^{2} \cdot \mathrm{h} \cdot$ bar and dye retentions of $93.7 \%$ for Rhodamine-B (molecular weight $=479 \mathrm{Da}$ ) and $90.8 \%$ for Erichrome black $\mathrm{T}$ (molecular weight $=461.38 \mathrm{Da}$ ) with $2.43 \mathrm{~L} / \mathrm{m}^{2} \cdot \mathrm{h} \cdot$ bar and $2.05 \mathrm{~L} / \mathrm{m}^{2} \cdot \mathrm{h} \cdot$ bar dye permeabilities, respectively. Wang et al. [4] assembled 8 layers of the poly(diallyldimethyl ammoniumchloride) (PDDA) and graphene oxide nanosheets at $40^{\circ} \mathrm{C}$ on a 30-40 kDa flat-sheet PAN UF membrane. The resulting membrane displayed $7.5 \mathrm{~L} / \mathrm{m}^{2} \cdot \mathrm{h} \cdot$ bar PWP and $>99 \%$ Methyl blue (molecular weight $=799.8 \mathrm{Da}$ ) and Congo red $(\mathrm{molec}-$ ular weight $=696.7 \mathrm{Da}$ ) dye rejections along with $6.42 \mathrm{~L} / \mathrm{m}^{2} \cdot \mathrm{h} \cdot \mathrm{bar}$ and $5.84 \mathrm{~L} / \mathrm{m}^{2} \cdot \mathrm{h} \cdot$ bar dye permeabilities. Wang et al. [5] first deposited the graphene oxide modified PEI and polyacrylic acid pair onto the 30-40 kDa PAN support, immersed the coated membrane in polyvinyl alcohol solution at $75^{\circ} \mathrm{C}$, andfinally crosslinked the membrane with glutaraldehyde. They reported complete dye retention of Methyl blue and Congo red with a 3-layered NF membrane, however, dye permeability was found to be very low $(<1 \mathrm{~L}$ / $\left.\mathrm{m}^{2} \cdot \mathrm{h} \cdot \mathrm{bar}\right)$. Kang et al. [6] produced a 4 layered composite membrane by coating PDDA/graphene oxide/PDDA/oxidized carbon nanotubes onto a PAN UF support membrane. Due to lack of negative charges on the surface, the support was first hydrolyzed in a $\mathrm{NaOH}$ solution at $55^{\circ} \mathrm{C}$ and carbon nanotubes were oxidized in a mixed solution of $\mathrm{H}_{2} \mathrm{SO}_{4} / \mathrm{HNO}_{3}$ at $70{ }^{\circ} \mathrm{C}$ for $8 \mathrm{~h}$. The Methyl blue and Light blue A (molecular weight $=690.8$ ) rejections from the membrane were reported as $99.3 \%$ and $97.9 \%$ while its PWP was $7.2 \mathrm{~L} / \mathrm{m}^{2} \cdot \mathrm{h} \cdot$ bar. Zhao and Wang manufactured a loose NF membrane by dip coating a $200 \mathrm{kDa}$ modified PAN support membrane with gallic acid grafted PEI at $45^{\circ} \mathrm{C}$ [7]. The composite membranes were then thermally cross-linked at $45^{\circ} \mathrm{C}, 55^{\circ} \mathrm{C}, 65^{\circ} \mathrm{C}$ and $75^{\circ} \mathrm{C}$. They reported $97.3 \%$ and $97.1 \%$ Methyl blue and Congo red dye rejection with relatively high dye permeability $\left(25.5 \mathrm{~L} / \mathrm{m}^{2} \cdot \mathrm{h} \cdot \mathrm{bar}\right)$ at optimized conditions. However, it was reported that plant phenolic compound gallic acid is not stable to high $\mathrm{pH}$ and easily degrades in aqueous solutions by $\mathrm{UV} / \mathrm{H}_{2} \mathrm{O}_{2}$ treatment [8,9]. This makes the long-term chemical stability of this membrane questionable. Prior studies have shown that in using the LbL technique an NF membrane for dye retention is achieved with more than one bilayer polyelectrolyte coating either through applying post treatment at high temperatures or pretreatment of the support/polyelectrolytes before deposition. In addition, the long term stability of these membranes was evaluated in terms of dye rejection and dye flux for a period between 30 and $60 \mathrm{~h}$. Their chemical stabilities, however, were not evaluated. The low dye permeabilites render these membranes non-competitive candidates for dye removal.

The objective of this study is to develop a high flux, stable, fouling resistant NF membrane which can be manufactured with an inexpensive and easily scalable method.We have adopted the LbL polyelectrolyte deposition technique due to its simplicity. The most important challenge for the new membrane is its stability while in the presence of either high salt concentrations or to chemicals used for foulant removal. In order to manufacture membranes stable in acidic and salt-rich environments, we have focused on both polyelectrolyte pair selection and deposition conditions. The support membrane was coated with PEI and alginate (ALG) weak polyelectrolytes under dynamic conditions at 1 bar. High activity of the carboxyl groups on ALG provides strong ionic cross-linking with the amine groups on PEI which is particularly strong in acidic environments [10-12]. Other challenges for the new membrane include: (1) the number of polyelectrolyte layers to convert UF membrane into a NF membrane (molecular weight cut off (MWCO):1 kDa), (2) the PWP ( $\left.\geq 10 \mathrm{~L} / \mathrm{m}^{2} \cdot \mathrm{h} \cdot \mathrm{bar}\right)$ higher than the $1 \mathrm{kDa}$ commercial NF membranes, (3) high dye permeance and (4) retention at maximum 2 bar operating pressure. To overcome these challenges, not only have the $\mathrm{pH}$ and ionic strength of the polyelectrolyte solutions been changed, but phase inversion conditions and the polymer composition have been varied for preparing the support membrane. The membrane exhibiting the highest PWP and $1 \mathrm{kDa}$ MWCO value was further investigated in terms of its rejection characteristics to different anionic dyes as well as its stability and fouling tendency. To the best of our knowledge, this study is the first which demonstrates the use of the PEI/ALG pair manufacturing a high flux and stable NF membrane with single bilayer deposition of these polyelectrolytes on a tight UF support without using any crosslinker.

\section{Experimental}

\subsection{Materials}

Polysulfone (PSF) with a molecular weight of $35 \mathrm{kDa}$ was purchased from Sigma Aldrich and sulfonated polyether sulfone (SPES) (80 kDa) was kindly donated by Konishi Chemicals, Japan. Solvent 1-methyl-2-pyrrolidone (NMP) purchased from Fluka with a purity of $>99.5 \%$ was used to dissolve PSF and SPES. Polyelectrolytes, PEI (molecular weight $=750 \mathrm{kDa}$ ) and alginic acid sodium salt from brown algae (ALG, molecular weight $=80-120 \mathrm{kDa}$ ) were supplied from Sigma Aldrich. Sodium hydroxide $(\mathrm{NaOH})$, sodium chloride $(\mathrm{NaCl})$ and hydrochloric acid $(\mathrm{HCl})$ with $37 \%$ purity were purchased from Sigma Aldrich and Merck, respectively. Polyethylene glycol (PEG) with a molecular weight of $1000 \mathrm{Da}$ was purchased from Aldrich and was used to perform the rejection tests. Anionic dyes, Procion Red H-E7B (CI Reactive red 141 (dye content of $>85 \%$ ), Brilliant blue $\mathrm{G}$ (dye content of $>60 \%$ ), and Methyl orange (dye content of $>85 \%$ ), were purchased from Dystar, Sigma Aldrich and Merck, respectively. Congo red (dye content of $>85 \%$ ) and Toluidine blue $\mathrm{O}$ (dye content of $>80 \%$ ), used for staining membranes, and bovine serum albumine (BSA) (molecular weight $=66 \mathrm{kDa}$ ), used to measure the fouling tendency of the membranes, were supplied by Sigma Aldrich.

\subsection{Membrane preparation}

\subsubsection{Support membrane preparation}

Support membranes were prepared from a blend of PSF and SPES polymers through the nonsolvent induced phase inversion method. The PSF:SPES ratio was adjusted to be either $5: 1$ or $4: 1$. Polymers were first dried overnight at $80^{\circ} \mathrm{C}$ and then dissolved in NMP by stirring at $150 \mathrm{rpm}$ for $24 \mathrm{~h}$. In order to eliminate air bubbles, the solution was held without stirring for $24 \mathrm{~h}$, and then cast on a clean defect free flat glass plate with the help of an automated film applicator (Sheen Instrument Ltd., model number: $1133 \mathrm{~N}$ ). The initial thickness of the cast film was adjusted by a four-sided applicator with a gap size of $250 \mu \mathrm{m}$. Following casting, 
the substrate was immediately immersed in a coagulation bath containing deionized water at $4{ }^{\circ} \mathrm{C}$. After a 10 -minute immersion in the coagulation bath, the membrane was rinsed and held in clean DI water at $4{ }^{\circ} \mathrm{C}$ for at least $24 \mathrm{~h}$ and finally stored in a refrigerator until further use.

\subsubsection{Polyelectrolyte deposition}

The bilayer polyelectrolyte assembly was formed on the negatively charged PSF/SPES support membrane in a dead end filtration unit (Millipore, Amicon Stirred Cell 8010) at 1 bar. A $1 \mathrm{~g} / \mathrm{L} \mathrm{PEI} \mathrm{solu-}$ tion was filtered for $10 \mathrm{~min}$. The membrane surface was then rinsed with $200 \mathrm{ml}$ DI water in order to remove weakly adsorbed polyelectrolyte. Following rinsing, the DI water was permeated through the membrane at 2.5 bar until steady state was reached. Afterwards, a $1 \mathrm{~g} / \mathrm{L}$ ALG solution was filtered through a PEIcoated membrane at 1 bar for $10 \mathrm{~min}$. Finally, the coated membrane was rinsed again with $200 \mathrm{ml}$ DI water. Throughout the manuscript, the membranes have been coded based on the $\mathrm{pH}$ of the polyelectrolyte solution. For example, $\mathrm{pH}$ 3/7 denotes a bilayer membrane prepared by depositing the first PEI layer at $\mathrm{pH} 3$ and the second ALG layer at $\mathrm{pH} 7$.

\subsection{Filtration experiments}

A dead-end cell filtration module with $10 \mathrm{ml}$ volume (Millipore 8010) was used to test the permeability and rejection properties of the membranes. A membrane with a surface area of $4.1 \mathrm{~cm}^{2}$ was initially pressurized at 2.5 bar until steady flux was achieved. Pure water was then filtered at 2 bar and the PWP of the membranes was calculated by the following equation:

$P W P=\frac{\Delta V}{A \Delta t \Delta P}$

where $\Delta V$ is the volume of permeated water $(\mathrm{L}), \mathrm{A}$ is the membrane area $\left(\mathrm{m}^{2}\right), \Delta t$ is the permeation time $(\mathrm{h})$ and $\Delta P$ is the transmembrane pressure difference (bar) applied through the membrane. The experiments were carried out at room temperature.

The rejection properties of the membranes were tested with PEG with a molecular weight of $1000 \mathrm{Da} .10 \mathrm{ml}$ of PEG solution $(1 \mathrm{~g} / \mathrm{L})$ was filtered at 2 bar until $5 \mathrm{ml}$ of permeate was collected (Stirring speed: $300 \mathrm{rpm}$ ). The same procedure was repeated three times with fresh solution under the same conditions to ensure that the membrane was fully conditioned with PEG 1000 . The concentrations of PEG 1000 in the stock solution $\left(C_{f}\right)$, permeate $\left(C_{p}\right)$ and in the retentate $\left(C_{r}\right)$ were determined using a Rudolph - J357 Automatic Refractometer. The observed rejection was calculated from:

$R(\%)=\left(1-\frac{C_{p}}{C_{B u l k}}\right) \times 100$

The bulk concentration in the dead end filtration module $\left(C_{B u l k}\right)$ changes with time due to the decrease in volume and increase in amount rejected by the membrane. In order to take the change in concentration on the feed side into account, an arithmetic average of the concentrations measured at the beginning $\left(C_{f}\right)$ and at the end of the rejection experiment $\left(C_{r}\right)$ were used as the bulk concentration in calculating the observed rejection coefficient [13]. Mehta and Zydney [14] reported that to avoid concentration polarization, the ratio of solution flux (Jv) to mass transfer coefficient (k) should be less than $10(\mathrm{Jv} / \mathrm{k}<10)$. For all the membranes prepared, this ratio has been found to be less than 1 which indicates the effect of concentration polarization is negligible.

Dye separation performance for the membrane which shows the highest permeability was investigated with the anionic dyes Reactive red 141, Brilliant blue G, Congo red and Methyl orange (Sterlitech HP4759 Stirred Cell). A 100 ppm dye solution was filtered through the $\mathrm{NF}$ membrane using a transmembrane differential pressure of 2 bar. The membrane had a surface area of $14.6 \mathrm{~cm}^{2}$. The concentration of the dye was measured by an ultraviolet spectrometer (Perkin Elmer, Lambda 25). During all of the filtration tests, measurements were taken with two different membrane samples to consider variations between the membranes. In addition, for each membrane, three successive measurements were conducted.

\subsection{Fouling measurement and stability test}

The fouling tendency and the stability of the most permeable membrane was investigated. For the fouling test, the PWP of the clean membrane $\left(P W P_{i}\right)$ was measured and then the stirred cell was refilled with BSA solution, i.e., with $1 \mathrm{~g} / \mathrm{L}$ concentration at $\mathrm{pH}$ of 7.0. The flux of the BSA solution permeating through the membrane was measured at 2 bar for $15 \mathrm{~h}$. At the end of filtration, the membrane was washed with distilled water for $10 \mathrm{~min}$ and the PWP $\left(P W P_{c}\right)$ was remeasured. The flux recovery (FR) was then calculated from:

$F R(\%)=\left(\frac{P W P_{c}}{P W P_{i}}\right) \times 100$

For the stability test, the membrane was stored in $1 \mathrm{M} \mathrm{NaCl}$ and in $\mathrm{HCl}(\mathrm{pH}=3)$ solution under static conditions. The PWP and PEG 1000 rejections from the membrane were measured at the end of 7 and 14 days of storage in $\mathrm{NaCl}$ solution, whereas those measurements were taken at the end of 5 and 14 days of storage in the $\mathrm{HCl}$ solution.

\subsection{Surface characterization methods}

Cross section and surface topography images of the dried membranes were analyzed by scanning electron microscope (SEM) using a FEI Quanta 250 FEG instrument. Before the analysis, dried samples were coated with gold with a Magnetron Sputter Coating Instrument. The surface roughness of the dried membranes was determined with atomic force microscope (AFM). Scanning was performed in tapping mode for a $5 \times 5 \mu \mathrm{m}$ surface using a TAP150 model tip (MMSPM Nanoscope 8 from Bruker).

The surface charge of the membranes was determined with dye staining and zeta potential measurements. For dye staining, PEI and ALG deposited membranes were immersed into $1 \mathrm{~g} / \mathrm{L}$ of negatively charged Congo red and positively charged Toluidine blue $\mathrm{O}$ solution each prepared at a $\mathrm{pH}$ of 7 . At the end of a $1 \mathrm{~h}$ immersion time, the membranes were washed with water until the effluent water became colorless. The intensity of color adsorbed on the membrane was measured with a spectrophotometer (AventesAvemouse62). Zeta potential measurements were carried out in the presence of a $10 \mathrm{mM} \mathrm{NaCl}$ solution with a NanoPlus Micromeritics Instrument. The $\mathrm{pH}$ value of the electrolyte solution was adjusted using $\mathrm{HCl}$ for acidic $\mathrm{pH}$ and $\mathrm{NaOH}$ for basic $\mathrm{pH}$. The water contact angle of the support membranes prepared with different blending ratios of PSF and SPES, was measured using an Attension Optical tensiometer. Before measurement, the membranes were dried and fixed on a glass slide. Four measurements were performed for each membrane with $5 \mu$ l liquid droplets.

\subsection{Pore size determination}

The pore sizes of the support and coated membranes were evaluated by analyzing the rejection data for PEG 1000 with Eqs. (4) through (8) [15]. Eq. (4) was derived for neutral solutes where the transport of solutes inside the membrane is governed by convection and diffusion. Although all the membranes prepared in this study are charged, since PEG 1000 is uncharged, its interaction 
with the pore wall is purely steric. Consequently, Eq. (4) is valid for modeling rejection of PEG 1000 and in characterizing the pore size of the membranes.

$$
\begin{aligned}
& R=1-\frac{C_{p}}{C_{\text {Bulk }}}=1-\frac{K_{i, c} \Phi}{1-\exp \left(-P_{e_{m}}\right)\left(1-\Phi K_{i, c}\right)} \\
& P_{e_{m}}=\frac{K_{i, c}}{K_{i, d}} \frac{V L}{D_{i, \infty} A} \quad \Phi=(1-\lambda)^{2} \quad \lambda=\frac{r_{s}}{r_{p}} \\
& K_{i, d}=K^{-1}(\lambda, 0) \quad K_{i, c}=(2-\Phi) G(\lambda, 0) \\
& K^{-1}=1-2.3 \lambda+1.154 \lambda^{2}+0.224 \lambda^{3}
\end{aligned}
$$$$
G(\lambda, 0)=1+0.054 \lambda-0.988 \lambda^{2}+0.441 \lambda^{3}
$$$$
\bar{A}=\frac{r_{p}^{2}}{8 \mu\left(\frac{J_{w}}{\Delta P}\right)}
$$

The parameters in Eqs. (4) through ( 9) are defined as follows: $\mathrm{D}_{\mathrm{i}, \infty}$ : bulk diffusivity $\left(\mathrm{m}^{2} \mathrm{~h}^{-1}\right), \mathrm{K}_{\mathrm{i}, \mathrm{c}}$ : hindrance factor for convection, $\mathrm{K}_{\mathrm{i}, \mathrm{d}}$ : hindrance factor for diffusion, $\Phi$ : steric partition term, $\mathrm{Pe}_{\mathrm{m}}$ : Peclet number, $\mathrm{V}$ : solute velocity $\left(\mathrm{m} \mathrm{h}^{-1}\right), \lambda$ : ratio of ionic or solute radius/pore radius $\mathrm{K}^{-1}$ : the hydrodynamic enhanced drag coefficient, $r_{s}$ : Stokes radius of ions and solutes $(m), r_{p}$ : effective pore radius (m), $\mathrm{G}$ : the hydrodynamic lag coefficient, $\mu$ : viscosity of solution (bar $\mathrm{h}$ ), $\mathrm{J}_{\mathrm{w}}$ : pure water flux based on membrane area $\left(\mathrm{m} \mathrm{h}^{-1}\right)$, L effective membrane to thickness ( $\left.\mathrm{m}\right)$, A: effective porosity of the membrane.

\section{Results and discussion}

\subsection{PWP and rejection properties of the membranes}

The support membrane for the polyelectrolytes deposition was manufactured from a blend of PSF and SPES through nonsolvent induced phase inversion. PSF was blended with SPES to increase its hydrophilic nature and impart negative charge to the membrane. Previous studies have shown that in order to obtain the pore size required for NF, several layers need to be deposited when UF supports with a MWCO $>20 \mathrm{kDa}$ are used [3,4]. To eliminate this disadvantage, a tight UF support membrane was prepared so that the pores on the surface could be easily covered and the pore size could be reduced to $\sim 1 \mathrm{~nm}$ with only a 2-layer deposition. This was achieved by coagulating a $25 \mathrm{wt} \%$ polymer solution (PSF:SPES $5: 1$ ) in pure water at $4{ }^{\circ} \mathrm{C}$. SEM images in Fig. 1 demonstrate that the support membrane has a typical finger like pores in the sublayer along with a thin dense skin layer forming $2.3 \%$ of the total thickness. As seen in Fig. 1c, the pores on the surface are too small to be determined even in the high magnification SEM image. The PWP and PEG 6000 rejection of the resulting membrane have been determined to be $27 \mathrm{~L} / \mathrm{m}^{2} \cdot \mathrm{h} \cdot$ bar and $99 \%$, respectively. Our support membrane has exhibited higher permeability than the commercial membrane with comparable MWCO manufactured from regenerated Cellulose (Table 1 ).

Current literature on the LbL method demonstrates that the $\mathrm{pH}$ and ionic strength of the polyelectrolyte solution used for depositing each layer can be adjusted to control the thickness and morphology of the assembly. This in turn determines the number of layers needed to obtain an NF membrane. In this respect, the deposition conditions for the first PEI layer have been changed and the effects of these changes on the PWP and PEG 1000 rejection have been investigated. Fig. 2 shows that the addition of saltincreases the PEG 1000 rejection without any significant change in the PWP. This can be explained by greater PEI adsorption in the presence of salt due to the screened segment/segment repulsion and enhanced surface/segment attractive interactions [19]. As shown in Scheme 1, the screening of polyion charges in high ionic strength environments results in a smaller radius of gyration $\left(R_{g}\right)$. Fewer coils, therefore, cover a lower surface area per chain leading to a larger area density of segments [20]. The zeta potential data in Fig. 3 demonstrate that the positive charge of the surface significantly increases when $\mathrm{NaCl}$ is added into the PEI coating solution. This indicates the presence of more $\mathrm{NH}_{3}{ }^{+}$groups on the surface due to greater PEI adsorption. The surface charge of the PEI-modified membranes was also determined by measuring the color intensity of the membranes stained with negatively charged Congo red that interacts electrostatically with the positively charged groups in PEI (Fig. 4). The stained membranes were washed continuously to eliminate nonspecific binding and to ensure that color intensities arise only from electrostatically attached dye molecules. The membranes prepared from the salt-containing PEI solution exhibit higher color intensities than the membranes deposited from saltfree PEI solution. This represents the increased presence of positively charged groups on the surface resulting due to more PEI adsorption in the presence of salt. Zeta potential measurements and dye staining have produced consistent results for the charge of the PEI deposited membranes in the presence and in the absence of salt. The staining technique provides not only the surface charge but also the charge distribution. The technique is not influenced by the ionic strength of the environment [21]. Consequently, only dye staining has been used to gain information on the charge of the surface after the second ALG layer deposition. Fig. 2 indicates that in the presence of $0.5 \mathrm{M} \mathrm{NaCl}$ in PEI solution, both the PEG rejection and PWP increase from $75.4 \pm 0.2 \%$ to $82.4 \pm 0.1 \%$ and from $12.6 \pm 0.1 \mathrm{~L} / \mathrm{m}^{2} \cdot \mathrm{h} \cdot$ bar to $14.1 \pm 0.1 \mathrm{~L} / \mathrm{m}^{2} \cdot \mathrm{h} \cdot$ bar when the deposition $\mathrm{pH}$ is changed from 7 to 3 . PEI is more protonated at $\mathrm{pH} 3$ than at $\mathrm{pH}$ 7. Thisinduces more ionic crosslinking with the negatively charged support and results in a thinner but more dense, layer

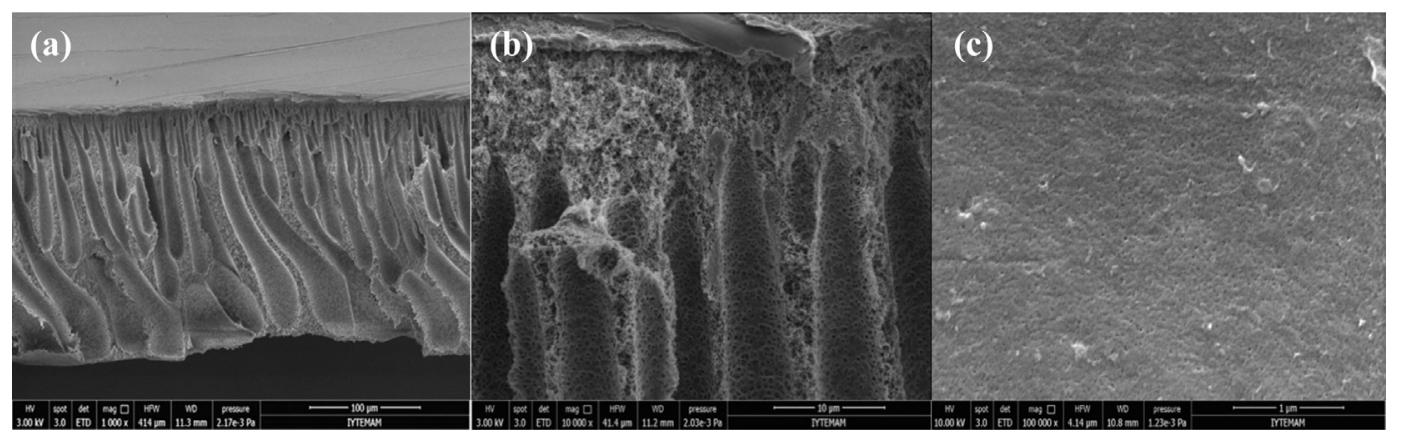

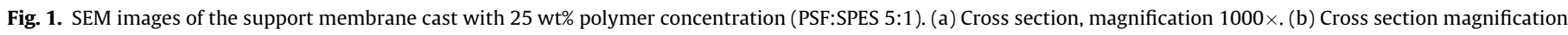
$10,000 \times$. (c) Surface magnification $100,000 \times$. 
Table 1

PWP of commercial UF and NF membranes.

\begin{tabular}{|c|c|c|c|c|c|c|}
\hline Supplier & Code & Type & MWCO (Da) & Permeability $\left(\mathrm{L} / \mathrm{m}^{2} \cdot \mathrm{h} \cdot\right.$ bar $)$ & Membrane & Ref \\
\hline Millipore Ultracel & PLC 5 & UF & 5000 & 14.5 & Regenerated Cellulose & {$[16]$} \\
\hline Millipore Ultracel & PLCC & UF & 5000 & 21.8 & Regenerated Cellulose & [16] \\
\hline Sartorius & $\mathrm{RC}$ & UF & 5000 & 20 & Regenerated Cellulose & [17] \\
\hline Sartorius & PES & UF & 5000 & 20 & Regenerated Cellulose & [17] \\
\hline GE Osmonics & GE & UF & 1000 & 1.11 & Composite Polyamide & [18] \\
\hline GE Osmonics & CK & $\mathrm{NF}$ & 2000 & 3.45 & Cellulose Acetate & [18] \\
\hline Microdyn Nadir & NP010 & $\mathrm{NF}$ & 1000 & $>5$ & PES & [18] \\
\hline Synder Filtration & NDX & NF & $800-1000$ & $10.1-12.3$ & Polyamide-TFC & [18] \\
\hline
\end{tabular}
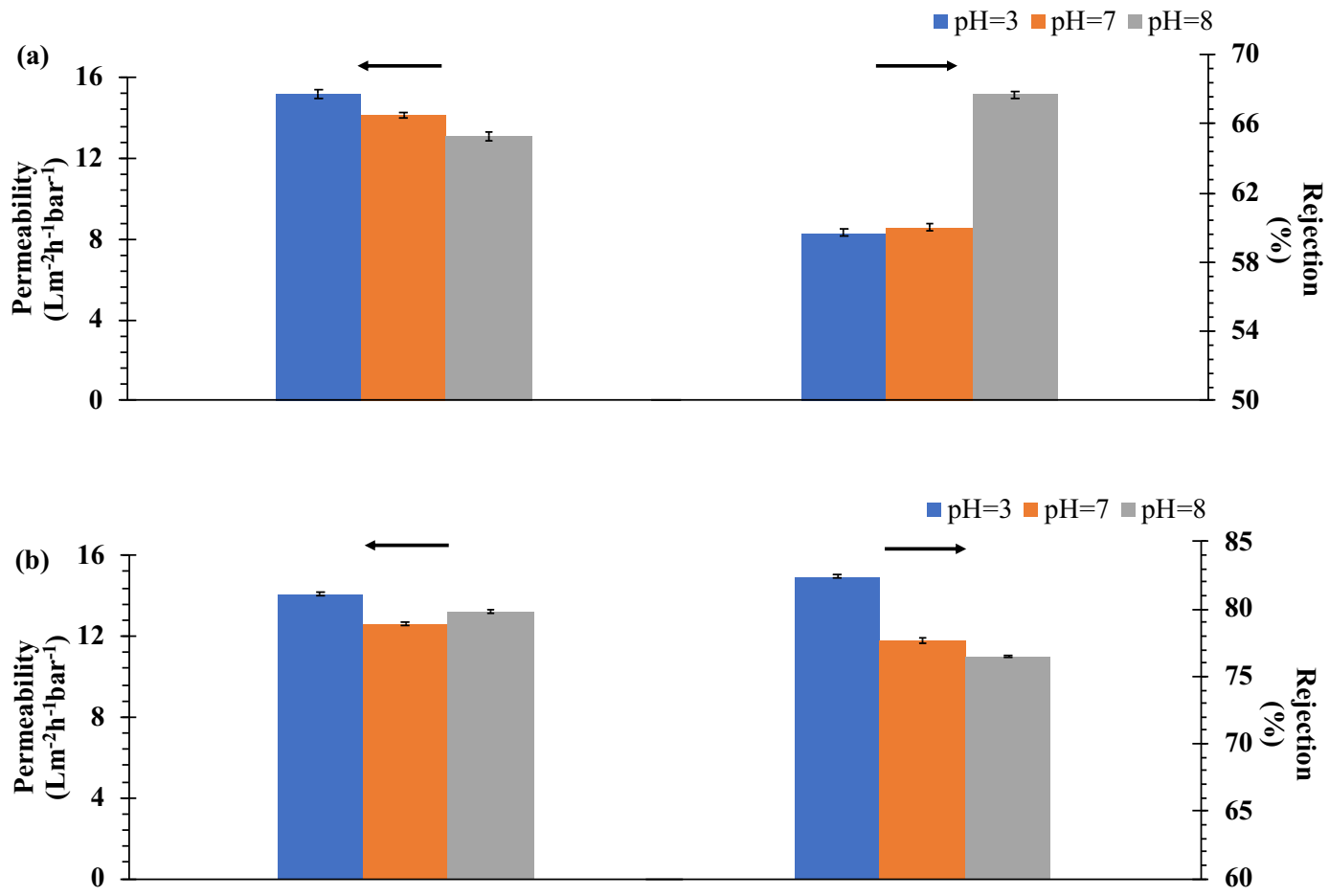

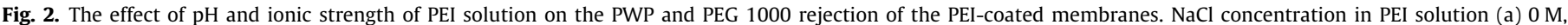
(b) $0.5 \mathrm{M}$.

(a)

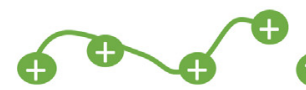

Negatively charged PSF/SPES (b)
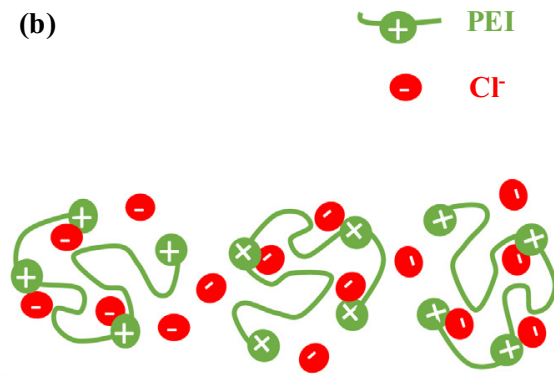

Negatively charged PSF/SPES

Scheme 1. Schematic representation of the effect of ionic strength of PEI solution on its adsorption. NaCl concentration in PEI solution (a) $0 \mathrm{M}$ and (b) $0.5 \mathrm{M}$.

formation and presumably leads to increased permeability and rejection. The trend is consistent with the general finding that highly charged chains adsorb in thin flat chain conformations. The typical tradeoff between the permeability and rejection has been observed for the membrane coated from a salt-free solution. In the absence of salt, where the screening effect of counterions does not exist, repulsion between the PEI chains at $\mathrm{pH} 3$ becomes more significant than at $\mathrm{pH} 8$, since PEI has a higher charge density at $\mathrm{pH}$ 3. This leads to less PEI adsorption, as confirmed by lower zeta potential (Fig. 3) and color intensity (Fig. 4), and thinner and less densified layer formation. Consequently, as shown in Fig. 2a, upon changing the deposition $\mathrm{pH}$ from 3 to 8 , an increase in the PEG 1000 rejection is accompanied by a decrease in the PWP (Scheme 2).

The membranes deposited at $\mathrm{pH} 7$ and 8 have shown similar permeability and rejection values $\left(\mathrm{pH}: 7 \quad 12.6 \pm 0.1 \mathrm{~L} / \mathrm{m}^{2} \cdot \mathrm{h} \cdot \mathrm{bar}\right.$, 


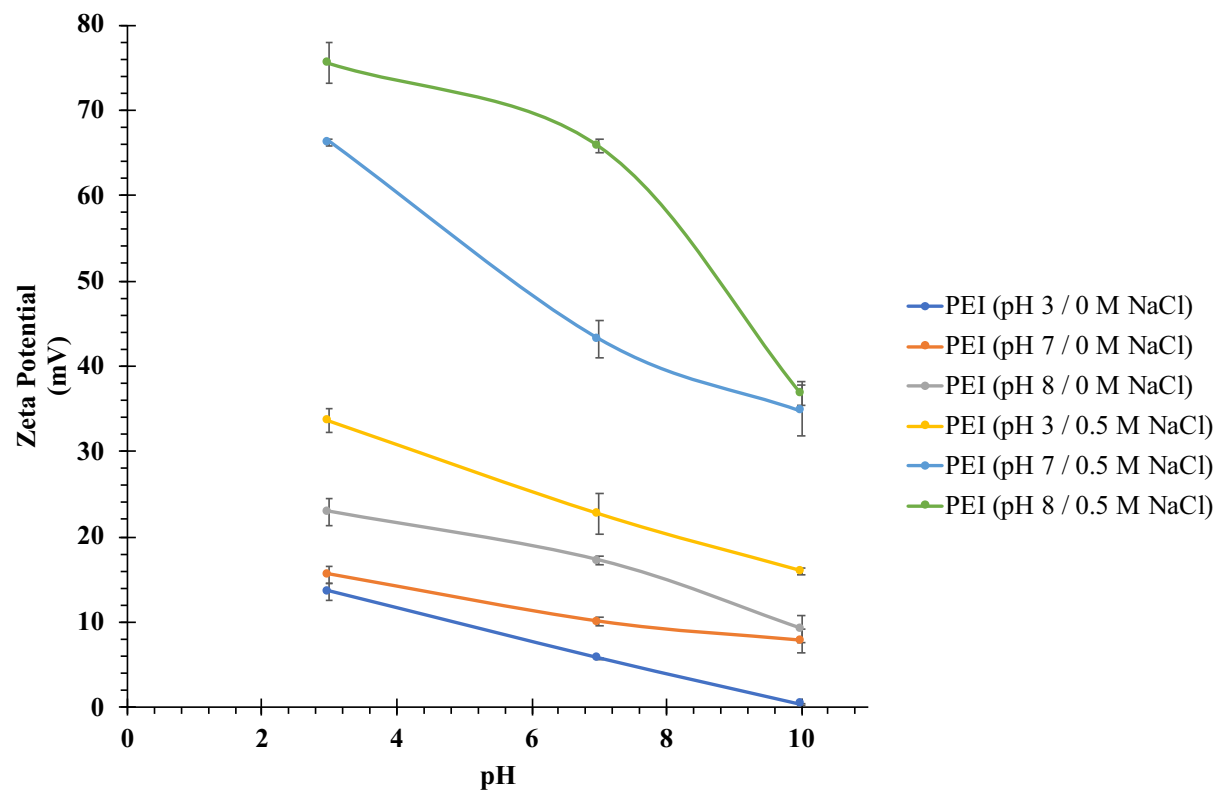

Fig. 3. Zeta potential as a function of $\mathrm{pH}$ for the PEI-deposited membranes prepared in the absence and presence of $0.5 \mathrm{M} \mathrm{NaCl}$ in deposition solution.

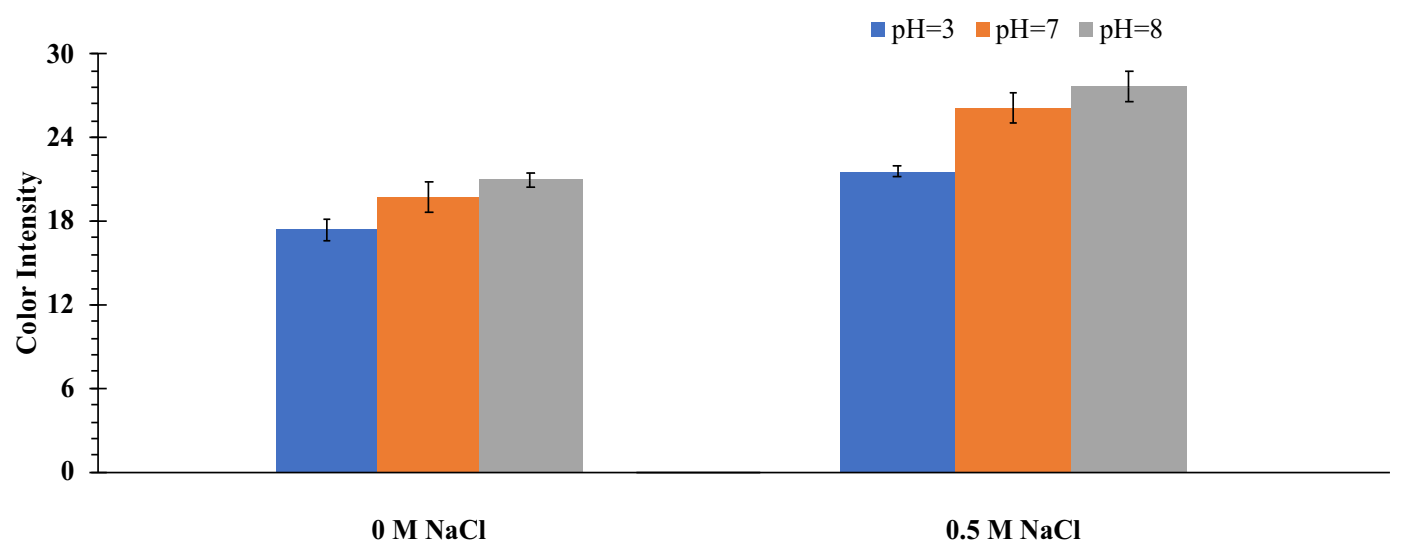

Fig. 4. Color intensity of PEI-deposited membranes in the absence and presence of $0.5 \mathrm{M} \mathrm{NaCl}$ in deposition solution.

(a)

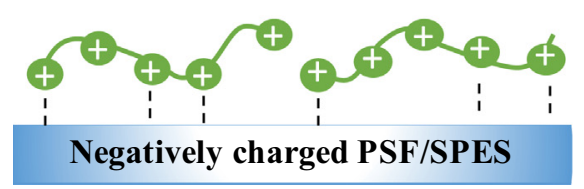

(b)

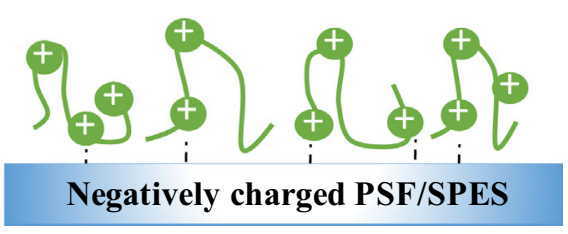

Scheme 2. Schematic representation of the effect of pH of PEI solution on its adsorption. (a) $\mathrm{pH}=3$ and (b) $\mathrm{pH}=7$.

$77.7 \pm 0.2 \%$ and $\left.\mathrm{pH}: 813.2 \pm 0.08 \mathrm{~L} / \mathrm{m}^{2} \cdot \mathrm{h} \cdot \mathrm{bar}, 76.5 \pm 0.1 \%\right)$ since the hydrodynamic radius $\left(\mathrm{R}_{\mathrm{h}}\right)$ and degree of protonation of PEI remain constant between $\mathrm{pH} 7$ and 9 [22]. The effects of pH and ionic strength of the PEI solution on the surface morphology of the coated membranes have been investigated by AFM. The adsorption of highly charged PEI (at $\mathrm{pH} 3$ ) results in thin, flat, compact and smooth surfaces in a rod-like configuration so as to minimize the electrostatic energy (see Fig. 5a and b). Lower charged PEI (at
$\mathrm{pH} 7$ ) forms thicker, rougher surfaces by adopting a coiled configuration (see Fig. 5c and d). This behavior was also observed by McAloney et al. [23], and Raposo and coworkers [24]. The salt screening causes a loopier structure as shown by the higher roughness of the membranes.

The results in Fig. 2 show that adding salt into PEI solution allows the surface pores to be covered more effectively and leads to higher PEG 1000 rejection. For this reason it was decided to 


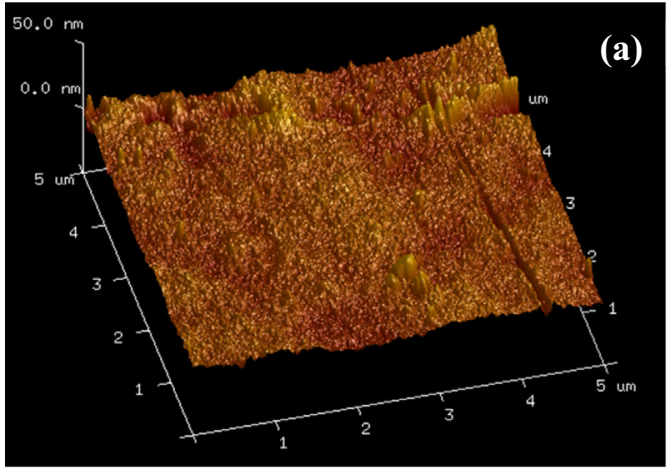

RMS Roughness $=2.44 \pm 0.1 \mathrm{~nm}$

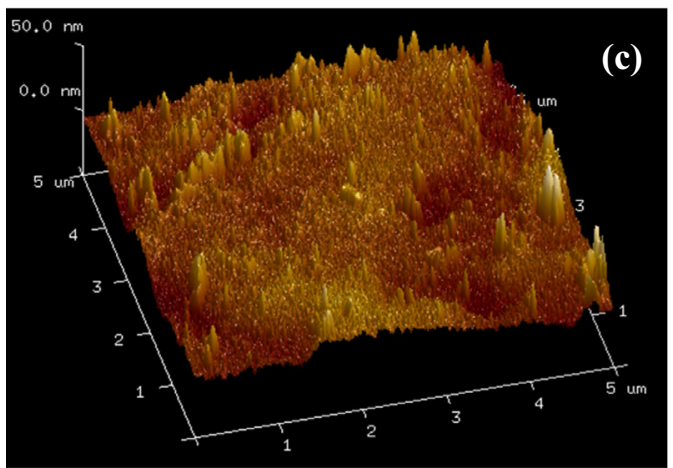

RMS Roughness $=3.48 \pm 0.19 \mathrm{~nm}$

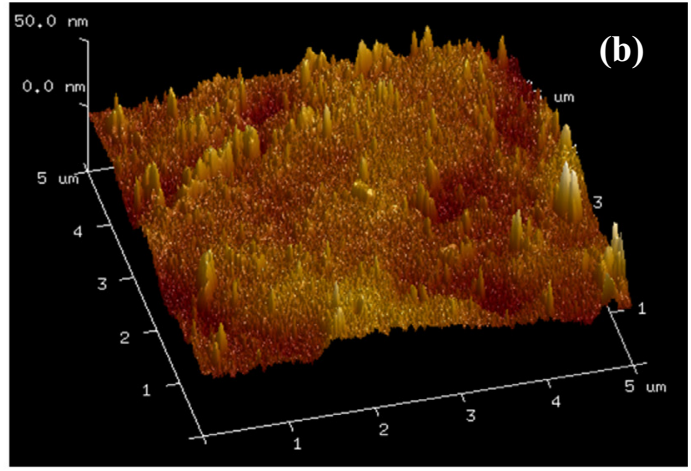

RMS Roughness $=2.72 \pm 0.16 \mathrm{~nm}$

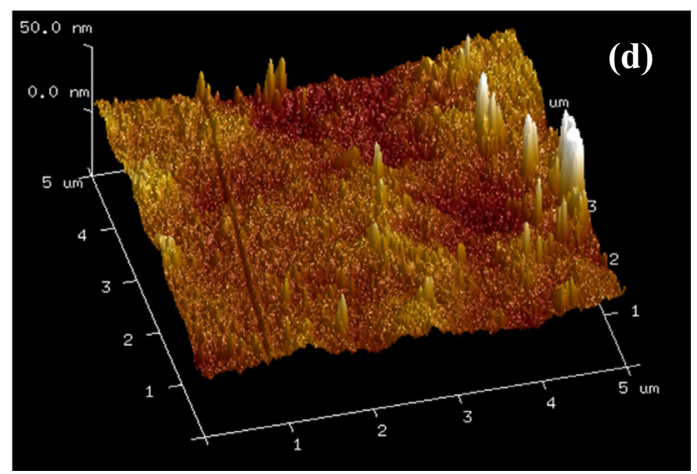

RMS Roughness $=4.1 \pm 0.34 \mathrm{~nm}$

Fig. 5. AFM images of the PEI-coated membranes (a) pH 3, $0 \mathrm{M} \mathrm{NaCl}$, (b) $\mathrm{pH} 3,0.5 \mathrm{M} \mathrm{NaCl}$, (c) pH 7, $0 \mathrm{M} \mathrm{NaCl}$, (d) pH 7, $0.5 \mathrm{M} \mathrm{NaCl}$.

always coat the second ALG layer on the PEI layer deposited from $0.5 \mathrm{M} \mathrm{NaCl}$ solution. Salt addition $(0.5 \mathrm{M} \mathrm{NaCl})$ into the ALG solution reduces the PEG 1000 rejection of the resulting membrane from $91.1 \pm 0.4 \%$ to $82.9 \pm 0.3 \%$. This is attributed to the swelling of the ALG chains [25]. Based on this result, ALG was coated only from salt-free solutions with the $\mathrm{pH}$ adjusted to 7 or 8 to achieve a high degree of crosslinking with the PEI layer (Scheme 3). The PEG 1000 rejection and PWP of the bilayer membranes, prepared from different $\mathrm{pH}$ combinations, are shown in Fig. 6. The [3/7] membrane which refers to the bilayer membrane assembled from alternating deposition of PEI solution at $\mathrm{pH} 3$ and ALG solution at $\mathrm{pH} 7$ has higher permeability $\left(11.6 \pm 0.2 \mathrm{~L} / \mathrm{m}^{2} \cdot \mathrm{h} \cdot \mathrm{bar}\right)$ and lower rejection $(87.5 \pm 0.1 \%)$ than the [7/7] membrane (4.7 \pm 0.01 $\mathrm{L} / \mathrm{m}^{2} \cdot \mathrm{h} \cdot$ bar and $\left.91.1 \pm 0.4 \%\right)$. This occurs due to greater ALG adsorptionand reduced pore size (Table 2 ) on going from deposition $\mathrm{pH}$ of $3 / 7$ to $7 / 7$. Compared to $\mathrm{pH} 3$, the higher charge density (Figs. 3 and 4) and roughness of the first PEI layer (Fig. 5) deposited at pH 7 allows for more ALG adsorption. As shown in Fig. 7, a higher color intensity of positively charged Toluidine blue $\mathrm{O}$ observed for the [7/7] membrane compared to the [3/7] membrane indicates the presence of more $\mathrm{COO}^{-}$groups on the surface confirming more ALG adsorption. Similarly, the higher rejection and lower permeability reported for the [7/7] membrane compared to the [8/7] membrane can also be explained by greater ALG adsorption, as confirmed by the higher color intensity observed on the [7/7] membrane (Fig. 7). As seen in Fig. 6, increasing the deposition $\mathrm{pH}$ for each layer from 7 to 8 leads to improvement in both the rejection and the PWP. The PEI layer and ALG have higher charges at $\mathrm{pH}$ 8 than at $\mathrm{pH}$ 7. This causes more ionic crosslinking between the PEI and ALG layers and accounts for improvement in the rejection. The thinner layer formation due to increased crosslinking explains the increase in the permeability.

The SPES content in the support membrane was increased in an attempt to further improve the PWP of the membranes without (a)

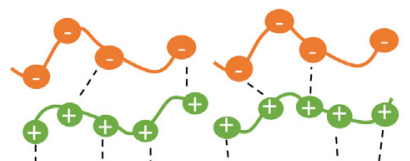

Negatively charged PSF/SPES (b)

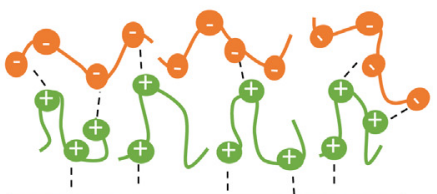

Negatively charged PSF/SPES (c)

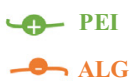

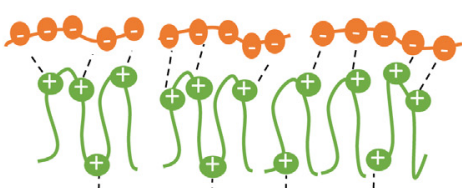

Negatively charged PSF/SPES

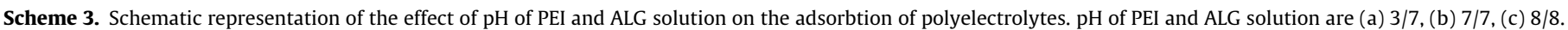




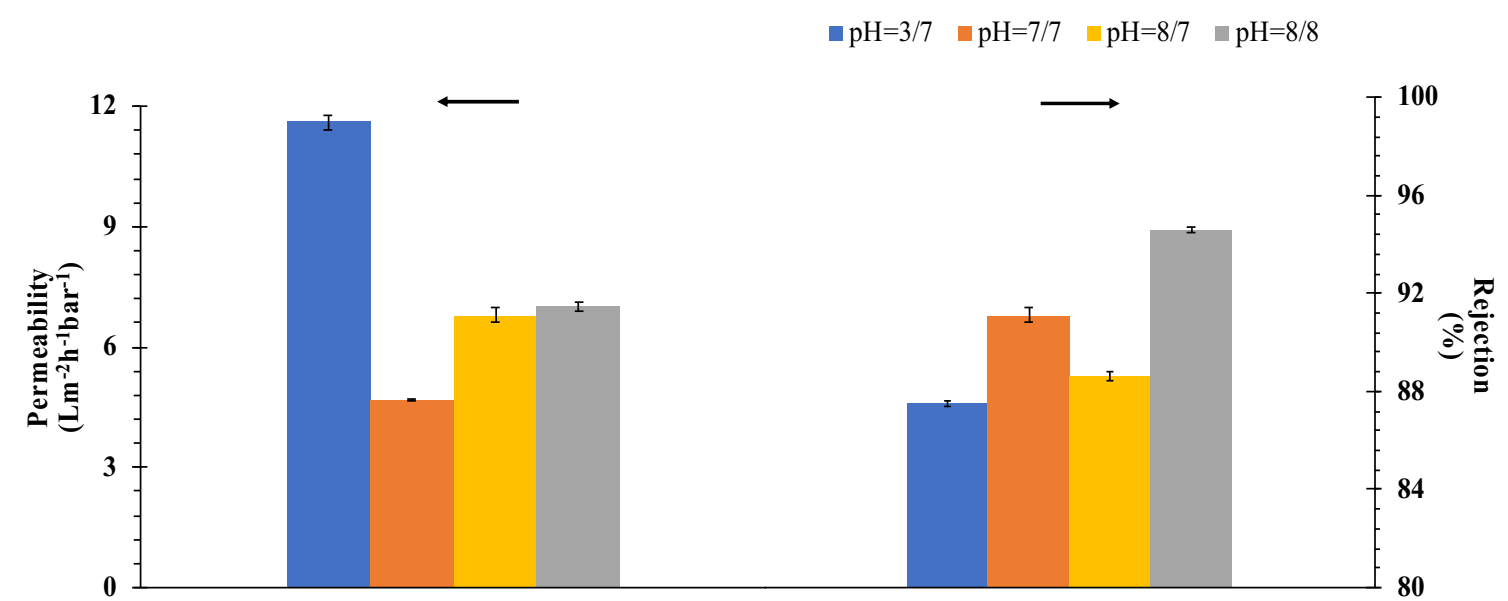

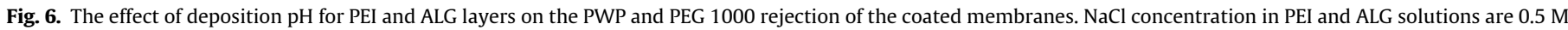
and $0 \mathrm{M}$, respectively. PSF:SPES ratio used in the preparation of support membrane is $5: 1$.

Table 2

Average pore size of the support and PEI/ALG coated membranes.

\begin{tabular}{|c|c|c|c|c|c|}
\hline \multirow[t]{2}{*}{ PSF:SPES ratio } & \multicolumn{2}{|c|}{ Deposition pH } & \multicolumn{2}{|c|}{$\begin{array}{l}\mathrm{NaCl} \text { concentration in } \\
\text { deposition solution }(\mathrm{M})\end{array}$} & \multirow[t]{2}{*}{ Pore size $(\mathrm{nm})$} \\
\hline & PEI & ALG & PEI & ALG & \\
\hline $5: 1$ & - & - & - & - & 1.83 \\
\hline $5: 1$ & 3 & 7 & 0.5 & - & 1.1 \\
\hline $5: 1$ & 7 & 7 & 0.5 & - & 0.82 \\
\hline $5: 1$ & 8 & 7 & 0.5 & - & 1.05 \\
\hline $5: 1$ & 8 & 8 & 0.5 & - & 0.99 \\
\hline $4: 1$ & - & - & - & - & 2.67 \\
\hline $4: 1$ & 3 & 7 & 0.5 & - & 1.31 \\
\hline $4: 1$ & 7 & 7 & 0.5 & - & 1.19 \\
\hline $4: 1$ & 8 & 7 & 0.5 & - & 1.23 \\
\hline $4: 1$ & 8 & 8 & 0.5 & - & 1.08 \\
\hline
\end{tabular}

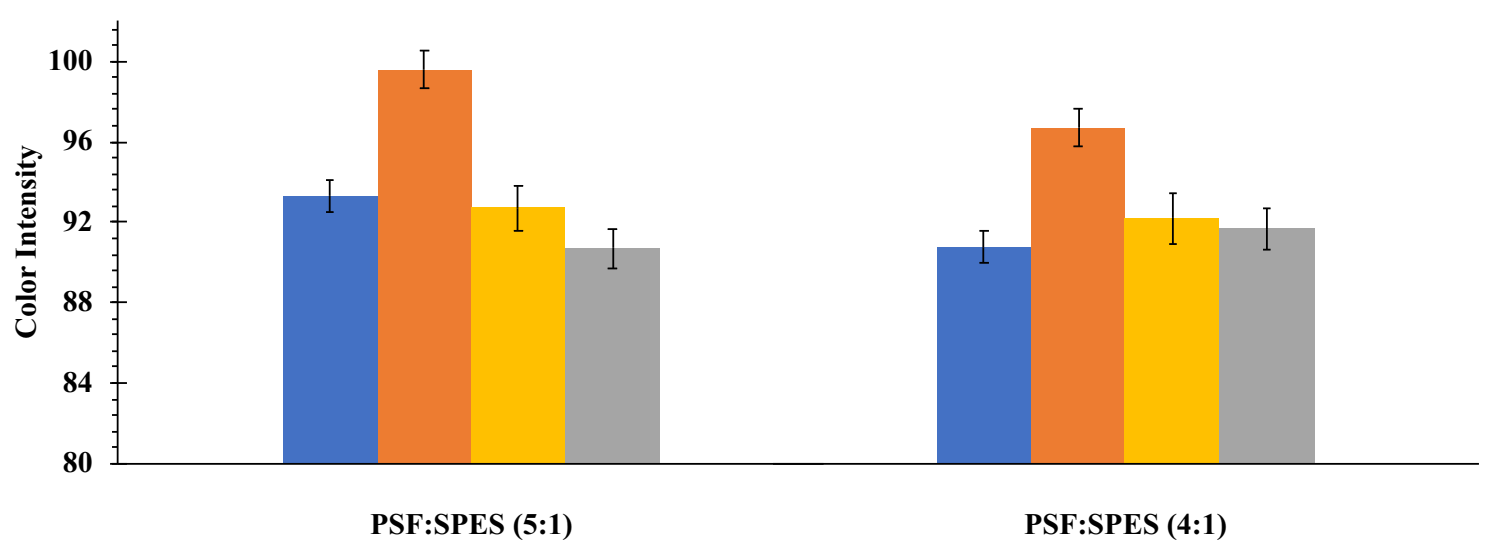

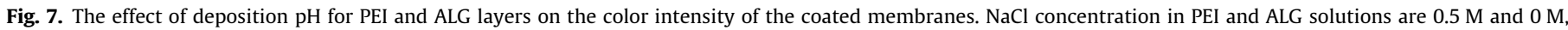
respectively.

lowering the PEG 1000 rejection to below 90\%. As shown in Fig. 8, the decrease in the water contact angle of the support membrane demonstrates the improvement of its hydrophilic character when the PSF:SPES ratio is changed from 5:1 to $4: 1$.

For coating the new support membrane (PSF:SPES 4:1), the $\mathrm{pH}$ of the PEI solution was adjusted to either 3,7 or 8 in the presence of $0.5 \mathrm{M} \mathrm{NaCl}$, whereas ALG was deposited at either $\mathrm{pH} 7$ or 8 without the use of salt. As shown in Fig. 9, the highest PWP $\left(15.5 \mathrm{~L} / \mathrm{m}^{2} \cdot \mathrm{h} \cdot \mathrm{bar}\right)$ and the PEG 1000 rejection (90\%) were obtained by setting the deposition $\mathrm{pH}$ to 8 for both polyelectrolytes. This can be attributed to a high degree of crosslinking and very thin layer formation due to strong charge-charge interactions between ALG and PEI. The results in Table 2 show that the pore size of the support membrane (PSF:SPES 4:1) has been reduced from $2.67 \mathrm{~nm}$ to $1.08 \mathrm{~nm}$ by depositing only two layers at $\mathrm{pH} 8$.

Table 1 lists the permeabilities of $1 \mathrm{kDa}$ commercial membranes manufactured by different companies. Compared with these commercial membranes, our optimized PEI/ALG coated NF membrane, 
(a)

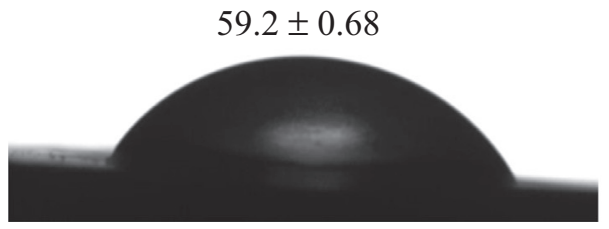

$4: 1$ (b)

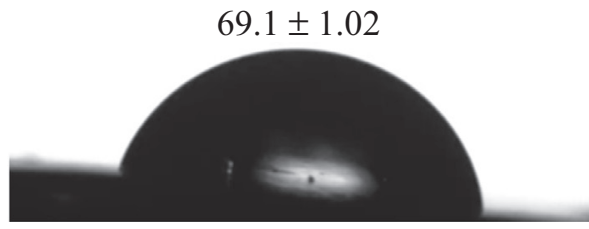

$5: 1$

Fig. 8. Water contact angle of the support membrane prepared with a PSF:SPES ratio of (a) 4:1 and (b) 5:1.

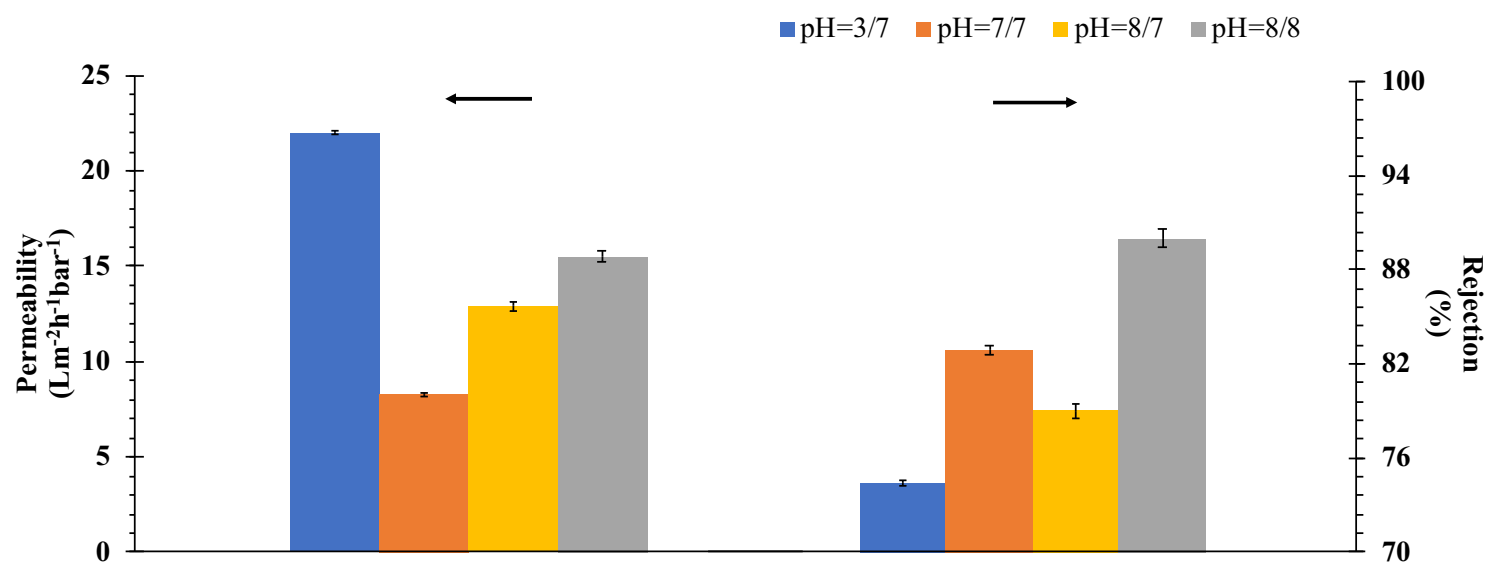

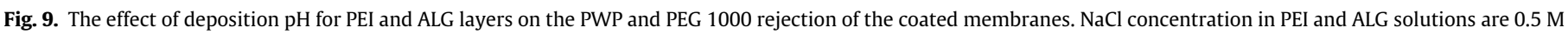
and $0 \mathrm{M}$, respectively. PSF:SPES ratio used in the preparation of support membrane is $4: 1$.

with the same MWCO value ( $1 \mathrm{kDa})$, exhibits higher permeability. Among the $1 \mathrm{kDa}$ commercial membranes, the highest permeability was reported for the Synder Filtration NDX membrane $\left(12.2 \mathrm{~L} / \mathrm{m}^{2} \cdot \mathrm{h} \cdot \mathrm{bar}\right)$. This value is $26 \%$ lower than the permeability of our best membrane $\left(15.5 \mathrm{~L} / \mathrm{m}^{2} \cdot \mathrm{h} \cdot\right.$ bar $)$. NDX is a polyamide TFC membrane prepared by interfacial polymerization of monomers dissolved in an organic phase. In contrast, the TFC membrane developed in this study was prepared by coating the support with water soluble polyelectrolytes.

\subsection{Dye removal performance of NF membrane}

Dye removal performance of the PEI/ALG coated membrane (MWCO: $1 \mathrm{kDa}$ ) showing the highest permeability (The [8/8] membrane coated on 4:1 PSF:SPES support) was tested by filtering $100 \mathrm{ppm}$ aqueous anionic dye solutions. The maximum absorption wave-length obtained from the ultraviolet spectrometer and the rejection characteristics of the dyes are listed in Table 3. Our negatively charged membrane can reject anionic dye molecules of Reactive red 141, Brilliant blue $G$ and Congo red completely as a result of both steric hindrance and electrostatic repulsion. Even though the molecular weight of Congo red (99\%) is lower than the MWCO of the membrane, its complete retention by the membrane demonstrates the dominance of the electrostatic interactions relative to the sieving effect. Fig. 10 shows the color of the dye solutions in the retentate and permeate streams at the end of filtration.

The percentage of flux decline corresponding to steady state level has been calculated. According to the data in Table 3, the smaller the flux decline, the smaller the molecular weight of dyes. The dye separation performance of our membrane was compared with that of other polyelectrolyte and commercial membranes (Table 4).

Although all the membranes have rejected $>99 \%$ of Congo red, in this work this rejection was achieved at 2 bar which is lower than the pressure used in previous investigations. In addition, the dye permeance of our membrane is higher than most of the other membranes listed in Table 4, which indicates that the retention of Congo red is achieved with a lower energy consumption. The effect of transmembrane pressure on the rejection of various dyes by $\mathrm{NF}$ membranes has been investigated by different groups [32-35]. In all these studies, an increase in dye rejection was observed with increased pressure. For example, Nataraj et al. [35] reported an enhancement in the Methyl orange rejection by a NF membrane from $94 \%$ to $98.9 \%$ by increasing pressure from 200 to 400 psia. The increase in dye retention with pressure was attributed to negligible effect of diffusion at high pressures on the transport of dye molecules compared to the transport by convection and electromigration [36].

Table 3

Dye removal performance of PEI/ALG coated NF membrane in filtration of $100 \mathrm{ppm}$ aqueous anionic dye solutions.

\begin{tabular}{|c|c|c|c|c|}
\hline Dye & Molecular weight (Da) & Maximum absorbance wavelength (nm) & Dye removal (\%) & Flux decline (\%) \\
\hline Reactive red 141 & 1774.19 & 543 & 99.9 & 12.2 \\
\hline Brilliant blue $G$ & 854.0 & 595 & 99.9 & 8.9 \\
\hline Congo red & 696.66 & 498 & 99.9 & 8 \\
\hline Methyl orange & 373.33 & 465 & 63.4 & 0.03 \\
\hline
\end{tabular}



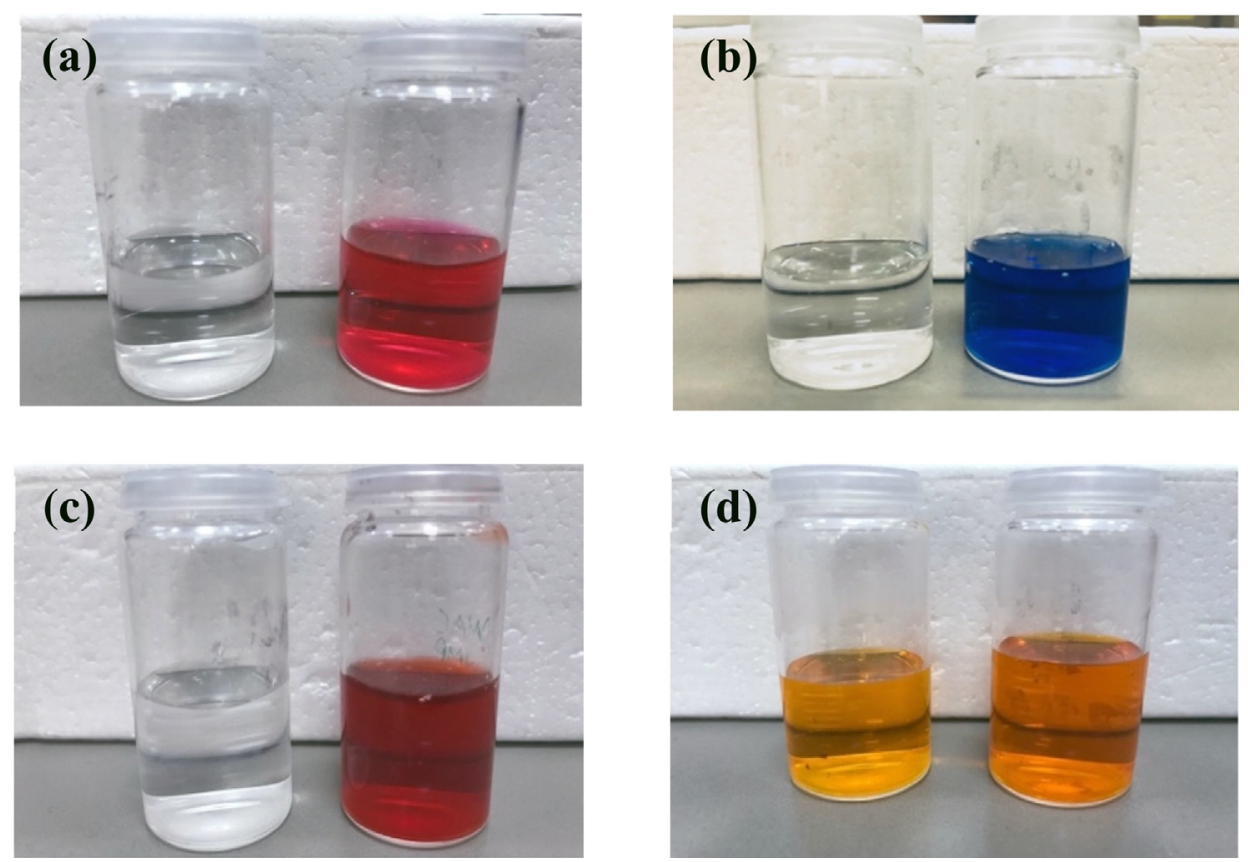

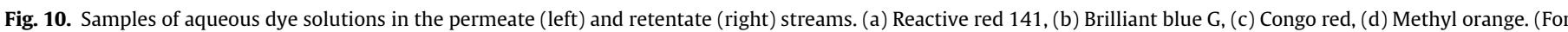
interpretation of the references to color in this figure legend, the reader is referred to the web version of this article.)

Table 4

Dye separation performances of different LbL coated polyelectrolyte and commercial NF membranes.

\begin{tabular}{|c|c|c|c|c|c|c|c|}
\hline Membrane (Layers)/Support & Dye & Conc. (g/L) & Flow condition & Retention (\%) & Permeance $\left(\mathrm{L} / \mathrm{m}^{2} \cdot \mathrm{h} \cdot\right.$ bar $)$ & Pressure (bar) & Ref \\
\hline (PDDA/GO)/PAN & Congo red & 0.1 & Cross flow & 99.9 & 5.84 & 5 & {$[4]$} \\
\hline \multirow[t]{2}{*}{ (PEI-GO/PAA/PVA/GA)/PAN } & Congo red & Not given & Dead-end & 99.5 & 0.84 & 5 & [5] \\
\hline & Methyl orange & & & 87.6 & 0.96 & & \\
\hline$(\mathrm{PEI}) / \mathrm{PAN}$ & Congo red & 0.1 & Cross flow & 97.1 & 25 & 2 & [7] \\
\hline$(\text { PS-PDMAEMA/PS-PMMA) })_{3.5} /$ PSF & Congo red & 0.1 & Dead-end & 98 & 11.6 & 3.45 & [26] \\
\hline (CMCNa/PEI)/PP hollow fiber & Congo red & 0.05 & Cross flow & 99.4 & 5.7 & 3 & [27] \\
\hline \multirow[t]{2}{*}{ 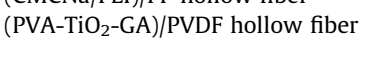 } & Congo red & 0.05 & Cross flow & 94 & 2 & 3 & [28] \\
\hline & Methyl orange & & & 52.1 & 3.7 & & \\
\hline$(\mathrm{GA} / \mathrm{PVA} / \mathrm{PAA})_{3} /$ ceramic membrane & Congo red & 0.1 & Tubular module & $>96$ & 4.2 & 6 & [29] \\
\hline (GA/CMCNa/GA/PVA)/PSF & Congo red & 0.05 & Cross flow & 99.5 & 14.9 & 5 & [30] \\
\hline Commercial Sepro NF 2A & Congo red & 0.1 & Cross flow & 99.96 & 9.6 & 6 & {$[31]$} \\
\hline Commercial Sepro NF 6 & Congo red & 0.1 & & 99.93 & 13.2 & & \\
\hline \multirow[t]{2}{*}{ (PEI/ALG)/PSF-SPES } & Congo red & 0.1 & Dead-end & 99.9 & 10 & 2 & This work \\
\hline & Methyl orange & & & 63.4 & 9.38 & & \\
\hline
\end{tabular}

\subsection{Antifouling property and stability of the membranes}

The fouling tendency of the optimized NF membrane was tested with BSA filtration for $15 \mathrm{~h}$. Fig. 11 compares the change of normalized BSA flux through a polyelectrolyte coated membrane and a commercial polyethersulfone membrane both having a MWCO value of $1 \mathrm{kDa}$. The commercial membrane shows a $20 \%$ decline in flux over the course of the filtration, whereas the PEI/ALG coated membrane exhibits a small decline ( $2 \%$ in $15 \mathrm{~h}$ ). The antifouling property of our membrane can be attributed to the hydrophilic nature of ALG which provides an increment in passage of the water molecules in the separation layer [37]. In addition, the Donnan exclusion mechanism also plays a key role for the antifouling property because BSA, which is negatively charged at $\mathrm{pH} 7$, is strongly repelled by the negatively charged outer layer of the membrane [27]. Flux recoveries of our membrane and the commercial one, after backwashing with water, were determined to be $92.5 \%$ and $87.5 \%$ respectively.

Zhao et al. [7] and Kang et al. [6] reported 35\% and 65\% flux declines in $100 \mathrm{~min}$ and $50 \mathrm{~min}$, respectively during $1 \mathrm{~g} / \mathrm{L}$ BSA filtration. A lower BSA flux decline (around 15\% in $6 \mathrm{~h}$ ) was observed

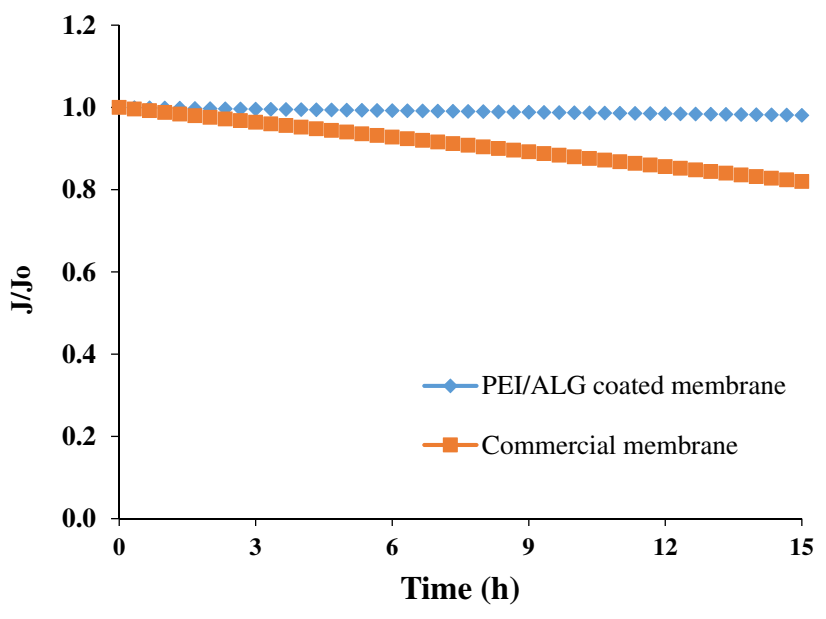

Fig. 11. The change of normalized BSA flux as a function of time in a dead-end filtration module. 
in the study of Wang et al. [4], however, the BSA concentration $(0.5 \mathrm{~g} / \mathrm{L})$ was half of that used in other studies. Compared to the performance of other polyelectrolyte membranes, the fouling tendency of our membrane is much lower even though a dead end filtration unit was used. For comparison, Zhao et al. [7] used cross flow unit. Fouling occurs at a higher rate in a dead end filtration unit than in a cross flow filtration mode.

The charge density of the polyelectrolytes and the ionic strength of the solution determine the strength of interactions between the polyelectrolytesand, consequently, the stability of deposited layers. Salt counterions participate in charge neutralization called extrinsic compensation when polyelectrolyte layers are in contact with a salt solution. This phenomena is shown with the following reversible ion exchange reaction [38]:

$\mathrm{Pol}^{+} \mathrm{Pol}_{\mathrm{m}}{ }^{-}+\mathrm{Na}_{\mathrm{aq}}{ }^{+}+\mathrm{Cl}_{\mathrm{aq}}{ }^{-} \Longleftrightarrow \mathrm{Pol}^{+} \mathrm{Cl}_{\mathrm{m}}{ }^{-}+\mathrm{Pol}^{-} \mathrm{Na}_{\mathrm{m}}{ }^{+}$

$K=\frac{y^{2}}{(1-y)[\mathrm{NaCl}]}=\left(\frac{y^{2}}{[\mathrm{NaCl}]_{a q}^{2}}\right)_{y \rightarrow 0}$

In these equations $m$ refers to $\mathrm{LbL}$ deposited layers, $K$ is the equilibrium constant for this reaction and $y$ refers to polyelectrolyte multilayers in extrinsically compensated form. At high salt concentrations in solution, the extrinsic charge compensation $\left(\mathrm{Pol}^{+} \mathrm{Cl}_{\mathrm{m}}^{-} \mathrm{Pol}^{-} \mathrm{Na}_{\mathrm{m}}^{+}\right)$becomes much more important than the intrinsic charge compensation $\left(\mathrm{Pol}^{+} \mathrm{Pol}_{\mathrm{m}}^{-}\right.$) between polyelectrolytes as a result of the increased charge screening along the polyelectrolyte chain. Consequently, the conformational change results in the formation of more coiled and loopy structures. This enhanced chain mobility, due to weaker electrostatic attraction between polyelectrolytes, may cause detachment of layers [39,40]. The stability of the optimized membrane has been tested by soaking it in $1 \mathrm{M} \mathrm{NaCl}$ solution up to 14 days. As shown in Fig. 12, no change has been observed in the PWP and PEG 1000 rejection of the membranes during 2 weeks of storage period. The results demonstrate excellent resistance to high salt concentration which can be attributed to strong electrostatic interaction between the layers as a result of a high charge density of both the adsorbed and adsorbing layer.

In addition to the salt stability measurement, chemical stability has been also tested by storing the optimized membrane in an $\mathrm{HCl}$ solution at pH 3. As illustrated in Fig. 13, the PWP of the membrane did not change during the two weeks of storage in the $\mathrm{HCl}$ solution and the PEG 1000 rejection decreased by only $17 \%$. The stability of the PEI/ALG coated membrane in acidic environment can be attributed to dense network formation between $-\mathrm{COO}^{-}$and $-\mathrm{NH}_{3}{ }^{+}$as a result of ionic crosslinking. Lower $\mathrm{pH}$ values provide more $\mathrm{H}^{+}$diffusion into the membrane protonating the $-\mathrm{NH}_{2}$ to $-\mathrm{NH}_{3}{ }^{+}$on the PEI [10].

\section{Conclusion}

In this study, a high flux NF membrane was prepared with a MWCO value of $1 \mathrm{kDa}$, by coating a single bilayer of the polyelectrolytes PEI and ALG on a PSF/SPES UF support. This membrane has demonstrated pure water permeability value significantly above those exhibited by $1 \mathrm{kDa}$ commercial membranes. In addition to the support membrane composition, the variation in $\mathrm{pH}$

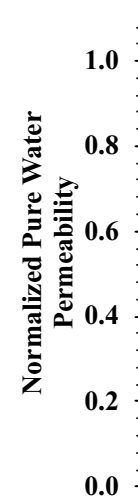

$\square$ Before Treatment After 7 days After 14 days
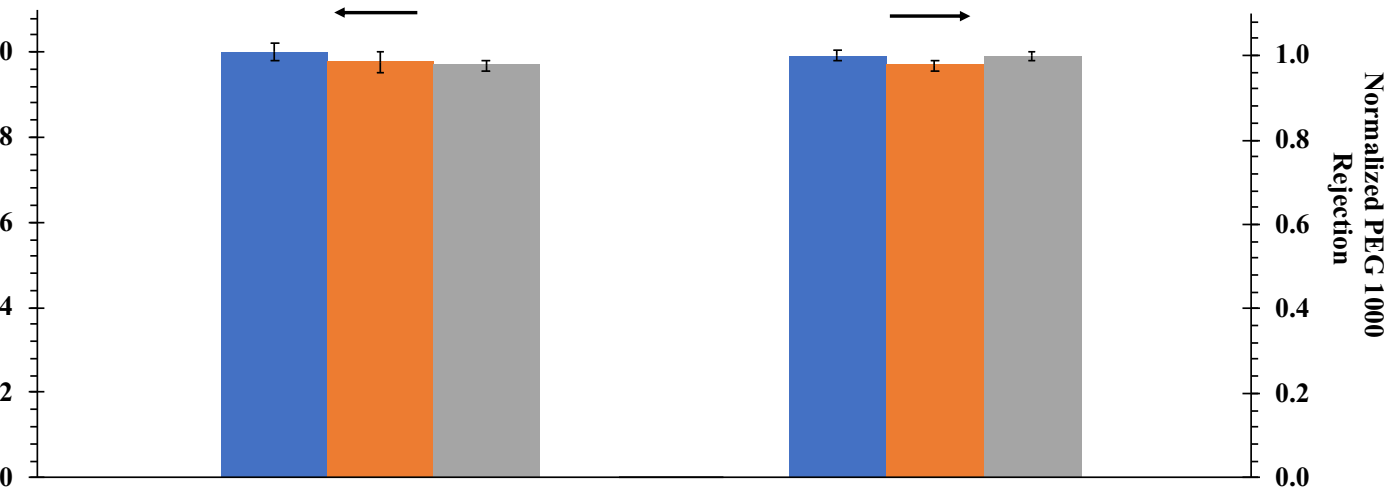

Fig. 12. The change of PWP and PEG 1000 rejection of the PEI/ALG coated membrane during storage in NaCl solution. Deposition pH for both layers is 8.

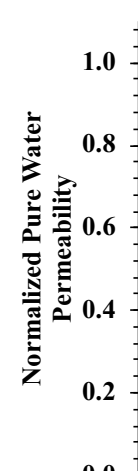

Before Treatment $\square$ After 5 days $\square$ After 14 days
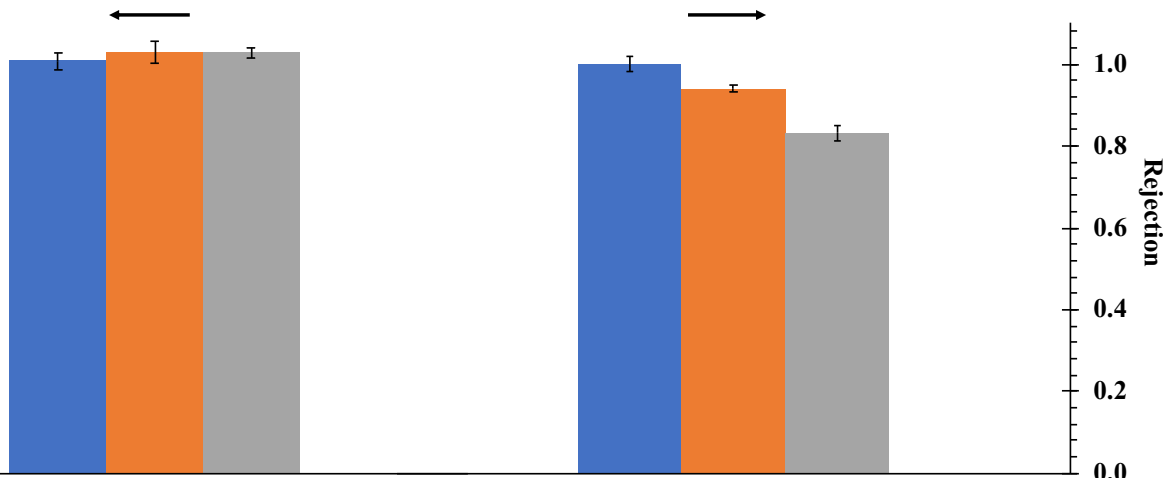

Fig. 13. The normalized flux and PEG 1000 rejection of the PEI/ALG coated membrane during storage in $\mathrm{HCl}$ solution ( $\mathrm{pH}=3$ ). Deposition $\mathrm{pH}$ for both layers is 8 . 
and ionic strength of the polyelectrolyte solution can be used to tailor the membrane performance, i.e., its permeability and rejection characteristics. Increasing the SPES content in the support membrane results in a more permeable membrane. Adding salt into the PEI solution covers the pores on the support surface more effectively and improves the PEG 1000 rejection. In contrast, salt addition into the ALG solution causes swelling of the chains and reduces rejection. The highest permeable membrane prepared rejects $99.9 \%$ of anionic dye molecules, Reactive red 141 , Brilliant blue $G$ and Congo red at 2 bar, shows little flux decline during BSA filtration, and exhibits excellent stability in high $\mathrm{NaCl}$ concentration. In addition, performance during long-term storage in acidic solution has not changed significantly indicating chemical stability.

In order to obtain an NF membrane with a single bilayer polyelectrolyte coating, we hypothesize that the following conditions need to be fulfilled: (1) A tight UF membrane should be used as a support. This can be easily prepared in a single step by controlling the phase inversion kinetics by changing the casting and coagulation bath conditions and requires no post treatment. (2) Salt should be added into the first layer polyelectrolyte solution if the polyelectrolyte does not swell significantly in the presence of salt. Adding salt will favor surface segment interactions and will lead to greater polyelectrolyte adsorption, i.e., more unbound free charge. In addition, in the presence of salt, the surface roughness will be higher which will increase the adsorption of the second polyelectrolyte. (3) The charge density of the polyelectrolyte solution, which will form the second layer, needs to be high to achieve a high degree of crosslinking. This will allow for thin layer formation, which is advantageous for minimizing flux decline, and will increase the stability of the layers in the presence of high salt concentration. (4) Salt should not be added into the second polyelectrolyte solution, in order to avoid thick and rough layer formation.

Compared to the previous polyelectrolyte coated membranes tested for dye retention, high dye permeance, few layers, short preparation time under dynamic conditions, no need for either pretreatment of the support/polyelectrolyte or post-treatment of the assembly are considered to be the key advantages of the membrane developed in this study. Furthermore, complete retention of Congo red at a low pressure is observed, which is an important economic issue. Diep et al. [26] coated cationic and anionic coreshell star block copolymers on a commercial polysulfone support in a layer-by-layer manner. After 3.5 bilayers coating, their membrane displayed $98 \%$ rejection for Congo red at 3.5 bar with a PWP of $11.6 \mathrm{~L} / \mathrm{m}^{2} \cdot \mathrm{h} \cdot$ bar. The retention of Congo red by our membrane is better than the commercial membranes Sepro NF 2A and Sepro NF 6. 99.9\% retention of Congo red by these membranes was achieved at 6 bar [31] while we achieve the same rejection at 2 bar. The commercial membranes are manufactured through a complicated interfacial polymerization. In contrast, the bilayer coated membrane developed in this study was fabricated through a simple dynamic coating method without the need of a crosslinker or activation of the support before coating.

The stability, high flux and antifouling properties, and ease of manufacturing make our membrane a potential candidate not only in the removal of dye molecules but also for the recovery of neutral/charged low molecular weight $(<1500)$ valuable compounds. In future studies, the antifouling property of this membrane will be examined with other foulants and the long-term of stability of the layers will be tested in a cross flow module while in the presence of high salt concentration.

\section{Acknowledgments}

We would like to thank the Material Research Center and Biotechnology and Bioengineering Application Research Center at the Izmir Institute of Technology for their kind help and technical support.

\section{References}

[1] B.W. Stanton, J.J. Harris, M.D. Miller, M.L. Bruening, Ultrathin multilayered polyelectrolyte films as nanofiltration membranes, Langmuir 19 (2003) 70387042.

[2] O. Sanyal, I. Lee, Recent progress in the applications of layer-by-layer assembly to the preparation of nanostructured ion-rejecting water purification membranes, J. Nanosci. Nanotechnol. 14 (2014) 2178-2189.

[3] H. Guo, M. Chen, Q. Liu, Z. Wang, S. Cui, G. Zhang, LbL assembly of sulfonated cyclohexanone-formaldehyde condensation polymer and poly(ethyleneimine) towards rejection of both cationic ions and dyes, Desalination 365 (2015) 108116.

[4] L. Wang, N. Wang, J. Li, J. Li, W. Bian, S. Ji, Layer-by-layer self-assembly of polycation/GO nanofiltration membrane with enhanced stability and fouling resistance, Sep. Purif. Technol. 160 (2016) 123-131.

[5] N. Wang, S. Ji, G. Zhang, J. Li, L. Wang, Self-assembly of graphene oxide and polyelectrolyte complex nanohybrid membranes for nanofiltration and pervaporation, Chem. Eng. J. 213 (2012) 318-329.

[6] H. Kang, J. Shi, L. Liu, M. Shan, Z. Xu, N. Li, J. Li, H. Lv, X. Qian, L. Zhao, Sandwich morphology and superior dye-removal performances for nanofiltration membranes self-assemblied via graphene oxide and carbon nanotubes, Appl. Surf. Sci. 428 (2018) 990-999.

[7] S. Zhao, Z. Wang, A loose nano-filtration membrane prepared by coating HPAN UF membrane with modified PEI for dye reuse and desalination, J. Memb. Sci. 524 (2017) 214-224.

[8] M. Friedman, H.S. Jürgens, Effect of $\mathrm{pH}$ on the stability of plant phenolic compounds, J. Agric. Food Chem. 48 (2000) 2101-2110.

[9] F.J. Benitez, F.J. Real, J.L. Acero, A.I. Leal, C. Garcia, Gallic acid degradation in aqueous solutions by $\mathrm{UV} / \mathrm{H}_{2} \mathrm{O}_{2}$ treatment, Fenton's reagent and the photoFenton system, J. Hazard. Mater. 126 (2005) 31-39.

[10] J. Li, X. Si, X. Li, N. Wang, Q. An, S. Ji, Preparation of acid-resistant PEI/SA composite membranes for the pervaporation dehydration of ethanol at low pH, Sep. Purif. Technol. 192 (2018) 205-212.

[11] B. Xiong, N. Wang, Y. Chen, H. Peng Self-assembly of alginate polyethyleneimine multilayer onto magnetic microspheres as an effective adsorbent for removal of anionic dyes, J. Appl. Polym. Sci. 135 (2018) 1-11.

[12] X. Sun, J.-H. Chen, Z. Su, Y. Huang, X. Dong, Highly effective removal of Cu (II) by a novel 3-aminopropyltriethoxysilane functionalized polyethyleneimine/sodium alginate porous membrane adsorbent, Chem. Eng. J. 290 (2016) 1-11.

[13] J. Luo, L. Ding, Y. Su, S. Wei, Y. Wan, Concentration polarization in concentrated saline solution during desalination of iron dextran by nanofiltration, J. Memb. Sci. 363 (2010) 170-179.

[14] A. Mehta, A.L. Zydney, Permeability and selectivity analysis for ultrafiltration membranes, J. Memb. Sci. 249 (2005) 245-249.

[15] W.R. Bowen, A.W. Mohammad, Characterization and prediction of nanofiltration membrane performance - a general assessment, Chem. Eng. Res. Des. 76 (1998) 885-893.

[16] Millipore Ultrafiltration Membranes. http://wolfson.huji.ac.il/purification/ PDF/dialysis/MILLIPORE_UltrafiltrationMembranes.pdf (accessed 3 February, 2018).

[17] S. Arénillas, M. Drouin, E. Monnin, P. Moulin, Glycerin removal from ultrafiltration flat sheet membranes by filtration and soaking, J. Memb. Sci. Res. 3 (2017) 102-108.

[18] Sterlitech Corporation, Flat Sheet Membranes. https://www.sterlitech.com/ flat-sheet-membranes.html/, (accessed 3 February, 2018).

[19] R. Meszaros, L. Thompson, M. Bos, P. de Groot, Adsorption and electrokinetic properties of polyethylenimine on silica surfaces, Langmuir 18 (2002) 61646169.

[20] M. Schonhoff, Layered polyelectrolyte complexes: physics of formation and molecular properties, J. Phys. Condens. Matter. 15 (2003) R1781-R1808.

[21] A. Tiraferri, M. Elimelech, Direct quantification of negatively charged functional groups on membrane surfaces, J. Memb. Sci. 389 (2012) 499-508.

[22] K.A. Curtis, D. Miller, P. Millard, S. Basu, F. Horkay, P.L. Chandran, Unusual salt and ph induced changes in polyethylenimine solutions, unusual salt and ph induced changes in polyethylenimine solutions, Plos One 11 (2016) 1-20.

[23] R.A. McAloney, M. Sinyor, V. Dudnik, M.C. Goh, Atomic force microscopy studies of salt effects on polyelectrolyte multilayer film morphology, Langmuir 17 (2001) 6655-6663.

[24] M. Raposo, Q. Ferreira, A.R.M. Timóteo, P.A. Ribeiro, A.M.B. do Rego, and Degree of ionization for birefringence creation and relaxation kinetics parameters of PAH/PAZO Films, J. Appl. Phys. 118 (2015) 114504

[25] S.T. Moe, G. Skjak-Braek, A. Elgsaeter, O. Smidsrad, Swelling of covalently crosslinked alginate gels: influence of ionic solutes and nonpolar solvents, Macromolecules 26 (1993) 3589-3597.

[26] J. Diep, A. Tek, L. Thompson, J. Frommer, R. Wang V. Piunova, J. Sly, Y.-H. La, Layer-by-layer assembled core-shell star block copolymers for fouling resistant water purification membranes, Polymer 103 (2016) 468-477.

[27] Q. Chen, P. Yu, W. Huang, S. Yu, M. Liu, C. Gao, High-flux composite hollow fiber nanofiltration membranes fabricated through layer-by-layer deposition of oppositely charged crosslinked polyelectrolytes for dye removal, J. Memb. Sci. 492 (2015) 312-321. 
[28] X. Li, Y. Chen, X. Hu, Y. Zhang, L. Hu, Desalination of dye solution utilizing PVA/ PVDF hollow fiber composite membrane modified with $\mathrm{TiO}_{2}$ nanoparticles, J Memb. Sci. 471 (2014) 118-129.

[29] L. Wang, N. Wang, G. Zhang, S. Ji, Covalent crosslinked assembly of tubular ceramic-based multilayer nanofiltration membranes for dye desalination, AlChE J. 59 (2013) 3834-3842.

[30] Y. Zhang, C. Yu, Z. Lü, S. Yu, Modification of polysulfone ultrafiltration membrane by sequential deposition of cross-linked poly (vinyl alcohol) (PVA) and sodium carboxymethyl cellulose $(\mathrm{CMCNa})$ for nanofiltration, Desalination Water Treat. 57 (2016) 17658-17669.

[31] J. Lin, W. Ye, H. Zeng, H. Yang, J. Shen, S. Darvishmanesh, P. Luis, A. Sotto, B.V der Bruggen, Fractionation of direct dyes and salts in aqueous solution using loose nanofiltration membranes, J. Memb. Sci. 477 (2015) 183-193.

[32] S. Yu, M. Liu, M. Ma, M. Qi, Z. Lü, C. Gao, Impacts of membrane properties on reactive dye removal from dye/salt mixture by asymmetric cellulose acetate and composite polyamide nanofiltration membranes, J. Memb. Sci. 350 (2009) 83-91.

[33] L. Wang, M. Fang, J. Liu, J. He, L. Deng, J. Li, J. Lei, The influence of dispersed phases on polyamide/ZIF-8 nanofiltration membranes for dye removal, RSC Adv. 5 (2015) 50942-50954.
[34] H. Kelewou, A. Lhassani, M. Merzouki, P. Drogui, Removal of textile-based dyes by nanofiltration:study of physicochemical parameters' effect on the retention by experimental designs methodology, Desalination Water Treat. 54 (2015) 1735-1746.

[35] S.K. Nataraj, K.M. Hosamani, T.M. Aminabhavi, Nanofiltration and reverse osmosis thin film composite membrane module for the removal of dye and salts from the simulated mixtures, Desalination 249 (2009) 12-17.

[36] J. Schaep, C. Vandecasteele, B. Peeters, J. Luyten, C. Dotremont, D. Roels, Characteristics and retention properties of a mesoporous gamma- $\mathrm{Al}_{2} \mathrm{O}_{3}$ membrane for nanofiltration, J. Memb. Sci. 163 (1999) 229-237.

[37] C.-H. Gu, J.-J. Wang, Y. Yu, H. Sun, N. Shuai, B. Wei, Biodegradable multilayer barrier films based on alginate/polyethyleneimine and biaxially oriented poly (lactic acid), Carbohydr. Polym. 92 (2013) 1579-1585.

[38] S.T. Dubas, J.B. Schlenoff, Swelling and smoothing of polyelectrolyte multilayers by salt, Langmuir 17 (2001) 7725-7727.

[39] N.G. Hoogeveen, M.A.C. Stuart, G.J. Fleer, Polyelectrolyte adsorption on oxides. 2. Reversibility and exchange, J. Colloid Interface Sci. 182 (1996) 146-157.

[40] M.R. Linford, M. Auch, H. Möhwald, Nonmonotonic effect of ionic strength on surface dye extraction during dye-polyelectrolyte multilayer formation, J. Am. Chem. Soc. 120 (1998) 178-182. 